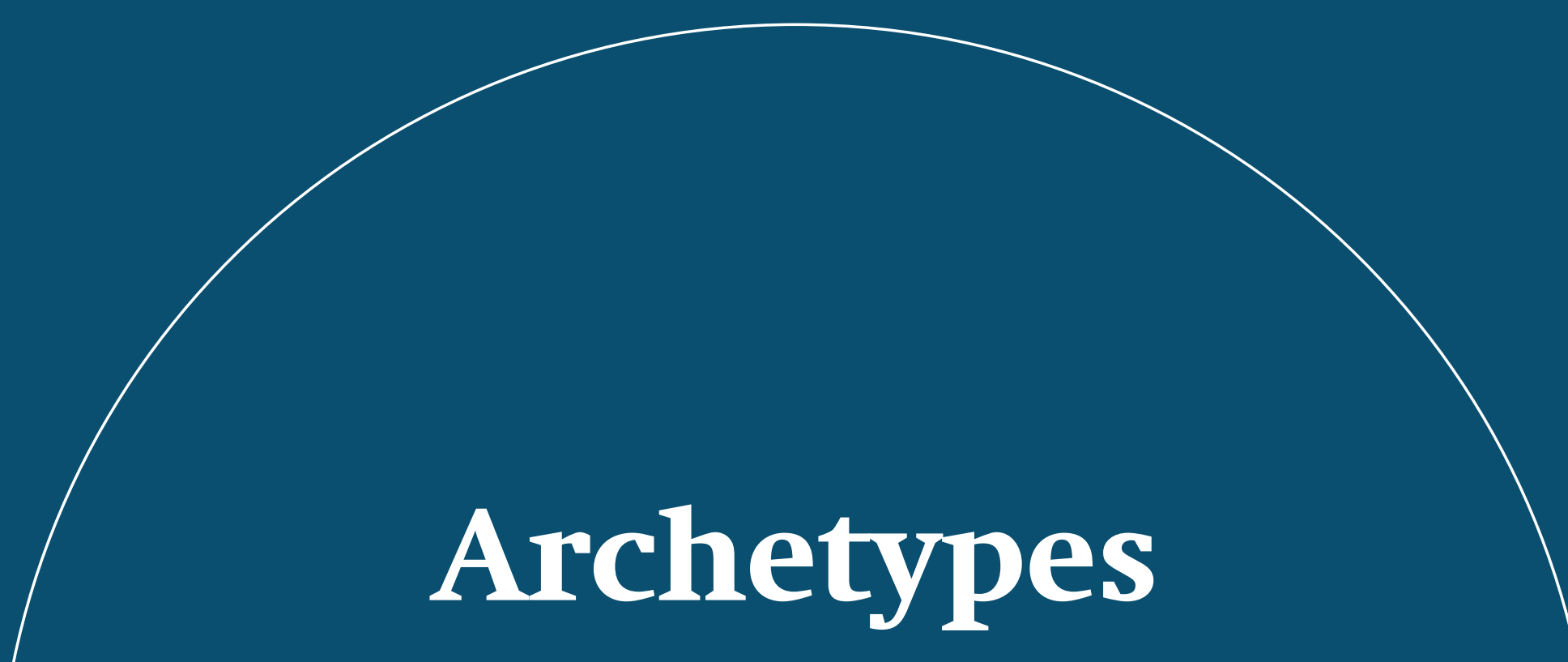

\title{
Common systemic behaviours in food systems
}

Helena Posthumus and Bart de Steenhuijsen-Piters

KIT Royal Tropical Institute

Just Dengerink and Sietze Vellema

Wageningen University \& Research 



\section{Archetypes}

Common systemic behaviours in food systems 
2018. Archetypes: common systemic behaviours in food systems. Wageningen, Wageningen University \& Research and KIT Royal Tropical Institute. 14 pp.

This report can be downloaded for free at https://doi.org/10.18174/464055 or at www.wur.eu/economic-research (under Wageningen Economic Research publications).

(C) 2018 Wageningen Economic Research

P.O. Box 29703, 2502 LS The Hague, The Netherlands, T +31 (0)70 33583 30,

E communications.ssg@wur.nl, http://www.wur.eu/economic-research. Wageningen Economic Research is part of Wageningen University \& Research.

\section{(cc) BY-NC}

For its reports, Wageningen Economic Research utilises a Creative Commons Attributions 3.0 Netherlands license.

(C) Wageningen Economic Research, part of Stichting Wageningen Research, 2018

The user may reproduce, distribute and share this work and make derivative works from it. Material by third parties which is used in the work and which are subject to intellectual property rights may not be used without prior permission from the relevant third party. The user must attribute the work by stating the name indicated by the author or licensor but may not do this in such a way as to create the impression that the author/licensor endorses the use of the work or the work of the user. The user may not use the work for commercial purposes.

Wageningen Economic Research accepts no liability for any damage resulting from the use of the results of this study or the application of the advice contained in it.

Wageningen Economic Research is ISO 9001:2008 certified.

Wageningen University \& Research and KIT Royal Tropical Institute | Project code 2282500299 


\section{Contents}

Archetypes: common systemic behaviours in food systems

Fixes that fail

Shifting the burden

Tragedy of the commons

Escalation

Growth and underinvestment 10

Limits to success

11

Success to the successful

Drifting goals 



\section{Archetypes: common systemic behaviours in food systems}

System archetypes represent generic behavioural patterns - or system dynamics - in any system. The concept of archetypes is mostly applied in the context of business management and organizational life. The term archetype was first coined by Peter Senge $(1990)^{1}$ in his seminal book 'The Fifth Discipline'. He uses systems thinking to convert companies into learning organizations; understanding complexity and reflective conservation are some of the key competences required to address complex problems. But similar archetypes of system behaviour can be found in food systems.

The use of archetypes assumes that, if the underlying systemic structure that results in specific behavioural patterns is understood, action can be taken to change the structure and thus systemic behaviour and consequently outcomes. Archetypes capture the 'common stories' in systems thinking; that is, dynamic phenomena that occur in diverse settings. The archetypes are used as templates for diagnosing complex problems (Kim, 2000). Below, eight archetypes are explained based on the work of $\operatorname{Kim}(2000)^{2}$.

Based on our own expertise and the information collected during a stakeholder workshop with food systems and FNS experts, we have provided examples of these archetypes in food systems. For each archetype, a set of leverage points is identified, which can offer solutions for the problematic behaviour captured by the archetype (Nguyen and Bosch, 2013). ${ }^{3}$

\footnotetext{
1 Senge P. 1990. The Fifth Discipline: the art and practice of the learning organization. Currency. ISBN 0-385-26095-4

2 Kim DH. 2000. Systems Archetypes I: diagnosing systemic issues and designing high-leverage interventions. Pegasus Communications Inc. ISBN 1-883823-00-5

3 Nguyen NC, Bosch OJH. 2013. A systems thinking approach to identify leverage points for sustainability: a case study in the Cat Ba Biosphere Reserve, Vietnam. Systems Research and Behavioral Science 30: 104-115. Doi: 10.1002/sres.2145
} 


\section{Fixes that fail}

In a 'fixes that fail' situation, a problem symptom cries out for resolution. A solution is quickly implemented that alleviates the symptom (B1), but the unintended consequences of the fix exacerbate the problem (R2) - with delay. Over time, the problem symptom returns to its previous level or becomes worse.

- Breaking a 'fixes that fail' cycle usually requires acknowledging that the fix is merely alleviating a symptom, and making a commitment to solve the real problem now.

- A two-pronged attack of applying the fix and planning out the solution will help ensure that you don't get caught in a perpetual cycle of solving yesterday solutions.

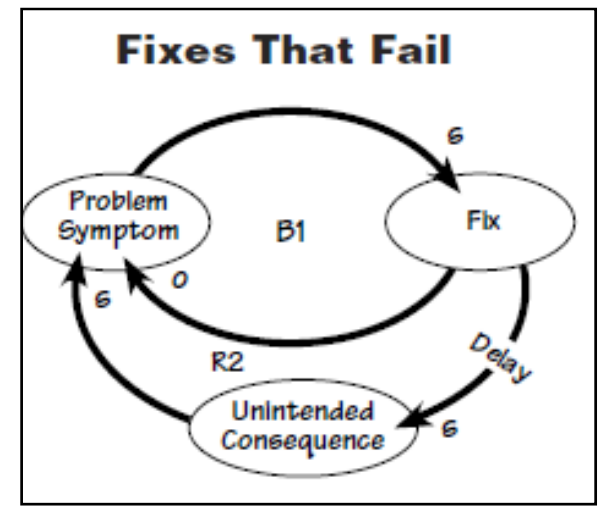

Examples in food systems:

Food assistance in regions with regular droughts, causing aid dependencies and declining investments in making agricultural systems or livelihoods more resilient to climate change. However, there are also successful cases of emergency systems (e.g. BCC and early case finding in Ethiopia/Kenya).

At global scale, there are conflicts of interest in international trade: market protection in Europe and especially dumping products elsewhere can exacerbate hunger and migration elsewhere.

Leverage points:

$>$ Focus on the long-term and if a fix is inevitably needed, use it only to buy time to work on the longterm remedy.

$>$ Raise awareness of the unintended consequences of the fixes.

$>$ Focus on the underlying problem and not the symptoms.

$>$ Find a way to measure the intended and also unintended consequences of the solutions by learning also from the past fixes. 


\section{Shifting the burden}

In a 'shifting the burden', a problem is 'solved' by applying a symptomatic solution (B1) which diverts attention away from more fundamental solutions (R3). In an addition structure, a 'shifting the burden' degrades into an addictive pattern in which the side-effect gets so entrenched that it overwhelms the original problem symptom.

- Problem symptoms are usually easier to recognize than the other elements of the structure.

- If the side-effect has become the problem, you may be dealing with an addiction structure.

Shifting the Burden/Addiction

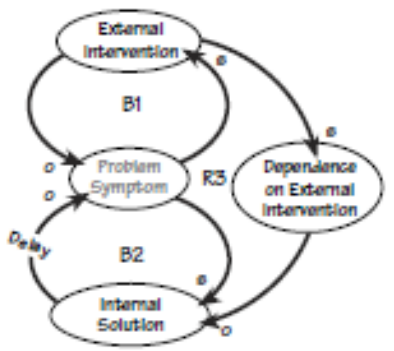

- Whether a solution is 'symptomatic' or 'fundamental' often depends on one's perspective. Explore the problem from a differing perspective in order to come to a more comprehensive understanding of what the fundamental solution may be.

\section{Examples in food systems:}

Subsidies for intensive agriculture resulting in negative environmental effects and depletion or pollution of resources.

Micronutrient powders (MNP, also called sprinklers produced by e.g. DSM) that results in short-term unsustainable fixes in building resilience of communities. Similarly there are concerns on the standard Vit A supplementation by UNICEF.

Contract farming for cash crops (e.g. barley for beer, irish potato, coffee). Cash crops may replace food crops resulting in higher incomes but simultaneously increasing malnutrition as people are reluctant to spent on (healthy, diverse!) food. (e.g. Sikasso paradox). The contemporary focus on nutrition-sensitive agriculture ${ }^{4}$ aims to overcome this system error.

Also related to the invisible informal economy and subsistence farming that are often destroyed when private sector parties are supported as solutions to alleviate poverty and hunger.

Leverage points:

$>$ Look beyond the symptoms to identify the root causes of the issue at hand.

$>$ Try to develop strategies (fundamental solutions) that address the root causes of the problem, instead of only the symptoms.

$>$ Employ both the symptomatic solution and the fundamental solution at the same time, (for example: Micro Nutrient Powders and Dietary Diversity + good Infant Young Child Feeding practices).

\footnotetext{
4 FAO 2014: Nutrition-sensitive agriculture is an approach that seeks to maximize agriculture's contribution to nutrition. This strategy stresses the multiple benefits derived from enjoying a variety of foods, recognizing the nutritional value of food for good nutrition, health and productivity, and the social significance of the food and agricultural sector for supporting rural livelihoods. Nutrition-sensitive agriculture also entails targeting poor households, promoting gender equity, and providing nutrition education so that household resources are used to improve household members' nutrition, especially that of women and young children. Finally, it involves linking agriculture to sectors that address other causes of malnutrition, namely education, health and social protection. (http://www.fao.org/about/meetings/icn2/newsarchive/news-detail/en/c/261494/)
} 


\section{Tragedy of the commons}

In a 'tragedy of the commons' structure, each person pursues actions which are individually beneficial ( $R 1$ and R2). If the amount of activity grows too large for the system to support, the commons experience diminishing benefits.

- Effective solutions for tragedy of the commons scenario never lie at the individual level.

- Ask questions such as: 'what are the incentives for individual to persist in their actions?' 'Can the long-term collective loss be made more real and immediate to the individual actors?'

- Find ways to reconcile short-term cumulative consequences. A governing body that is chartered with

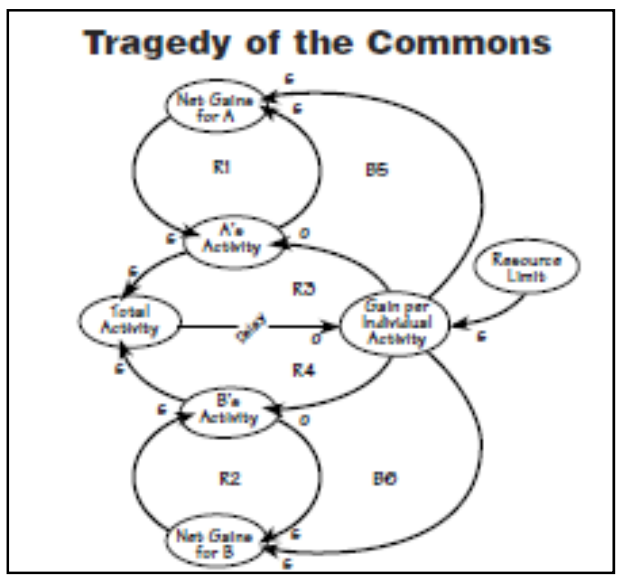
the sustainability of the resources limit can help.

\section{Example in food systems:}

This is a key archetype in current food systems. This is addressed in NL by e.g. VoedselAnders and now the Transitie Coalitie Voedsel which aims to accelerate progress on True cost/True price (internalizing externalities). Examples are:

- Degradation of natural resources, overgrazing.

- Greenhouse gas emissions by transport/fertilizer for intensive agriculture (and cows!).

Leverage points:

$>$ Organize communities to organize communal resources together through self-regulation.

$>$ Privatization of resources giving the owner incentives to enforce its sustainability.

$>$ Government regulation (legislation, treaties) and enforcement to prohibit individual behaviour damaging the commons.

$>$ Internalizing negative externalities in the price of products. 


\section{Escalation}

In the 'escalation' archetype, one party (A) takes actions that are perceived by the other as a threat. The other party $(B)$ responds in a similar manner, increasing the threat to $A$ and resulting in more threatening actions by $A$. To break an escalation structure, ask the following questions:

- What is the relative measure that pits one party against the other and can you change it?

- What are the significant delays in the system that may distort the true nature of the threat?

- What are the deep-rooted assumptions that lie beneath the actions taken in response to the threat?

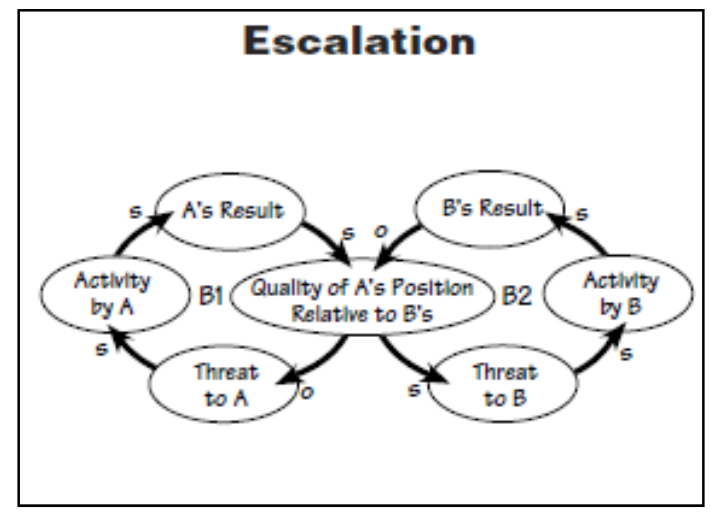

Examples in food systems:

opposing actor groups in conflict; trade wars; ethnic tensions; up- vs downstream water users; cattle raids.

Leverage points:

$>$ Break the spiral effect of escalation through changing the rules of the system (mediation, bylaws, consultation, etc.).

$>$ Change the rules of the systems in ways that encourage cooperation and give little space for competition.

$>$ Address the worldviews and presumptions that are underlying the increasing threat levels from both sides. 


\section{Growth and underinvestment}

In a 'growth and underinvestment' archetype, growth approaches a limit that can be eliminated or pushed into the future if capacity investments are made. Instead, performance standards are lowered to justify underinvestment, leading to lower performance which further justifies underinvestment.

- Dig into the assumptions which drive capacity investment decisions. If past performance dominates as a consideration, try to balance that perspective with a fresh look at demand and the factors that drive its growth.

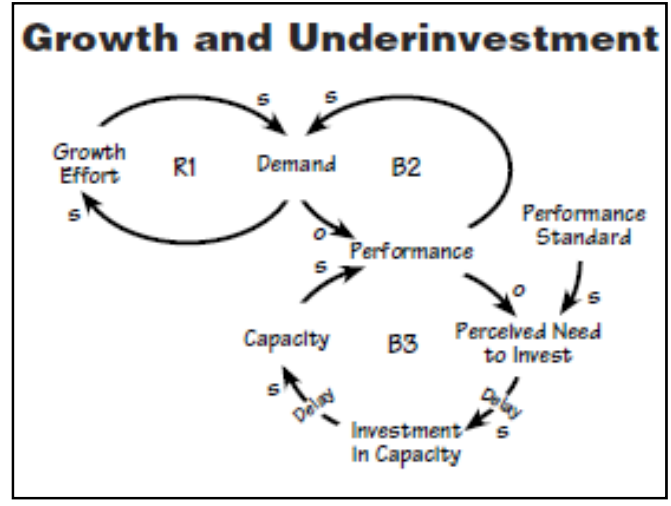

- If there is potential for growth, build capacity in anticipation of future demand.

Examples in food systems:

Underinvestment in agricultural services for smallholder farming; lack of investments towards more sustainable production.

Leverage points:

$>$ Increase the amount of investment, in order to prevent the quality of services and the demand for these services to decrease.

$>$ Improve capacity planning in order to identify possibilities for increased investment. 


\section{Limits to success}

In a 'limits to success' scenario, continued efforts initially lead to improved performance. Over time, however, the system encounters a limit which causes the performance to slow down or even decline (B2), even as efforts continue to rise.

- The archetype is most helpful when it is used well in advance of any problems, to see how the cumulative effects of continued success might lead to future problems.

- Use the archetype to explore questions such as 'what kinds of pressures are building up in the system as a result of the growth?'

- Look for ways to relieve pressures by strengthening the balancing loops (slowing down unsustainable exponential growth), or remove system limits to allow further growth before a system gasket blows.

Examples in food systems:

In Europe: the focus is still on bulk production to avoid hunger, with all the negative effects on health and environment that we see now.

Leverage points:

$>$ Identify the limiting conditions that drive the reinforcing loop that slow down the desired action.

$>$ Try to influence the limiting condition by weakening or eliminating it.

$>$ If this is not possible, try to identify new reinforcing loops that support and help grow towards the desired state. 


\section{Success to the successful}

In a 'success to the successful' archetype, if one person or group $(A)$ is given more resources, it has a higher likelihood of succeeding than $B$ (assuming they are equally capable). The initial success justifies devoting more resources to $A$, and $B$ 's success diminishes, further justifying more resource allocations to A (R2).

- Look for reasons why the system was set up to create just on winner.

- Chop off one half of the archetype by focussing efforts and resources on one group, rather than creating a 'winner-take-all' competition.

- Find ways to make collaborators rather than competitors.

- Identify goals or objectives that define success at a level higher than the individual players $A$ and $B$.

\section{Example in food systems:}

Dutch agri-businesses in agri-sector in developing countries. Preference for Dutch private sector partners (from the 'Dutch diamond') instead of local SMEs and cooperations. The large players tend to benefit most from partnership facilities and funds (e.g. SDG facility). The grants are too large to be managed by smaller players.

Other example at local level are project beneficiaries: model farmers, beneficiary farmer groups, etc.

Leverage points:

$>$ Implement regulation to ensure there is fair and equal competition between different actors, giving less successful actors sufficient chances to grow.

$>$ Try to find ways to decouple the activities of the two actors, in ways that they both have equal access to resources.

$>$ Redefine success: not profit (or return on investment) as main success indicator but equality, creating employment opportunities, increasing affordable access to healthy food. 


\section{Drifting goals}

In a 'drifting goals' archetype, a gap between the goal and current reality can be resolved by taking corrective action (B1) or lowering the goal (B2). The critical difference is that lowering the goal immediately closes the gap, whereas corrective actions usually take time.

- Drifting performance figures are usually indicators that the 'drifting goals' archetype is at work and that real corrective actions are not being taken.

- A critical aspect of avoiding a potential 'drifting goals' scenario is to determine what drives the setting of the goals.

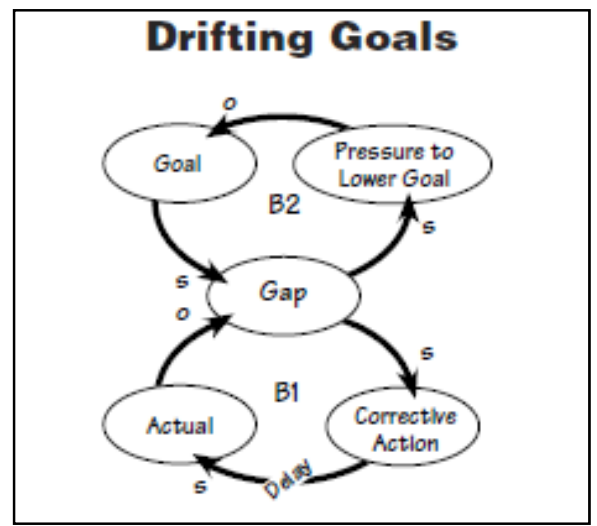

Examples in food systems:

Setting no hunger by 2030 (SDG2) as policy objective might be overly ambitious. Prevalence of undernourishment is estimated at $31.4 \%$ in East Africa (SOFI, 2018). Breaking down ambitious policy goals in short-term targets can help.

UNICEF and WHO use Average Annual Reduction Rates (AARRs) to monitor progress on the reduction of stunting. In Ethiopia, the AARR is estimated at $2.17 \%$, but it should be $4.75 \%$ to reduce the number of stunted children from 6.13 million to 3.68 million in 2025 (World Health Assembly target) ${ }^{5}$.

Leverage points:

$>$ Realistic expectations in goal setting - goals that are set too high reduce incentives to achieve them.

$>$ Increase corrective actions to reduce the gap between the current state and the desired state.

$>$ Be more explicit about the different steps needed to achieve this particular goal. 
Wageningen Economic Research P.O. Box 29703

2502 LS The Hague

The Netherlands

$\mathrm{T}+31(0) 703358330$

E communications.ssg@wur.nl

www.wur.eu/economic-research

Wageningen Economic Research MEMORANDUM
The mission of Wageningen University \& Research is "To explore the potential of nature to improve the quality of life". Under the banner Wageningen University \& Research, Wageningen University and the specialised research institutes of the Wageningen Research Foundation have joined forces in contributing to finding solutions to important questions in the domain of healthy food and living environment. With its roughly 30 branches, 5,000 employees and 10,000 students, Wageningen University \& Research is one of the leading organisations in its domain. The unique Wageningen approach lies in its integrated approach to issues and the collaboration between different disciplines.

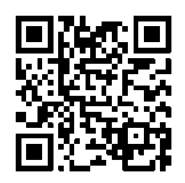

